\title{
Genetic variation in the diamondback moth, Plutella xylostella (Lepidoptera: Yponomeutidae) in China inferred from mitochondrial $\mathrm{COI}$ gene sequence
}

\author{
Jianhong LI ${ }^{1}$, Feng ZHAO ${ }^{1}$, Yong Soo $\mathrm{CHOI}^{2}$, Iksoo KIM ${ }^{3}$, Hung Dae SOHN ${ }^{2}$ and Byung Rae JIN ${ }^{2 *}$ \\ ${ }^{1}$ Department of Plant Protection, Huazhong Agricultural University, Wuhan, Hubei 430070, China \\ ${ }^{2}$ College of Natural Resources and Life Science, Dong-A University, Busan 604-714, Korea \\ ${ }^{3}$ Department of Agricultural Biology, The National Institute of Agricultural Science \& Technology, Suwon 441-100, Korea
}

Key words. Diamondback moths, Plutella xylostella, insect pest, mitochondrial DNA, COI gene, geographic variation

\begin{abstract}
The diamondback moth, Plutella xylostella (L.), is a notorious insect pest of cruciferous plants. To examine the pattern and magnitude of genetic variation in this species in China a portion of the mitochondrial (mt) COI gene of $P$. xylostella, collected at six Chinese and two Korean localities, which cover $\sim 2,151,600 \mathrm{~km}^{2}$, was sequenced. Sequence analysis of the 681 -bp $\mathrm{mt} C O I \mathrm{gene}$ from 80 individuals resulted in 16 haplotypes, ranging in sequence divergence from $0.1 \%$ (one nucleotide) to $0.9 \%$ (six nucleotides). One nucleotide position among 16 variable sites was a transversional substitution and the remaining positions were transitional substitutions. No position resulted in amino acid substitution. Phylogenetic analysis showed that all haplotypes were highly interrelated and no discernable haplotype group was found. From a geographical perspective, most haplotypes were found singly at one or two localities, with three haplotypes widely distributed. Little genetic differentiation $\left(F_{\mathrm{ST}}=-0.038-0.309\right)$ and a high rate of female migration $(\mathrm{Nm}=1.117$ - infinite) between Chinese populations suggests that dispersal over long distances is a major factor in the demography of this species.
\end{abstract}

\section{INTRODUCTION}

The diamondback moth, Plutella xylostella (L.), is a world-widely distributed insect pest of cruciferous plants and the damage caused by its larvae amounts to at least one-billion dollars annually (Talekar \& Shelton, 1993). A high number of generations per year, great dispersal ability and resistance to pesticides are characteristics of this insect pest (Lorimer, 1981; Talekar \& Shelton, 1993; Baker \& Kovaliski, 1999; Kim et al., 1999; Capinera, 2001; Huang \& Wu, 2003).

Knowledge of the genetic aspects of geographic variation and population structure of an insect pest may provide important biological information for developing optimal control strategies. Nevertheless, such studies on diamondback moths are limited to a small number of populations and regions of the world (Caprio \& Tabashnik, 1992; Chang et al., 1997; Kim et al., 2003).

In China, cruciferous plants are widely cultivated and the diamondback moth is one of the most damaging pests (Lu et al., 2003). However, there is no molecular study on the Chinese populations of $P$. xylostalla. As the first step in the collecting of genetic information on the diamondback moth in China the mitochondrial DNA (mtDNA) could be a good molecular marker for providing the magnitude and pattern of genetic diversity over such a wide area.

MtDNA has a high evolutionary rate compared to the functional counterpart of nuclear DNA. In addition, it is inherited maternally, does not undergo genetic recombination and is easy to handle (Brown et al., 1982; Harrison, 1989). These characteristics make the mtDNA molecule a particularly appropriate marker for tracing the recent evolutionary history of animals (Wilson et al., 1985). Among the several genes in the mtDNA cytochrome oxidase subunit I (COI) gene is highly variable at the DNA level, especially at the silent sites (Simon et al., 1994).

In this study, a portion of (681 bp) mt COI gene from 80 individuals of $P$. xylostella collected at six Chinese and two Korean localities was sequenced. These localities cover approximately $\sim 2,151,600 \mathrm{~km}^{2}$ and the minimum distance between them is $410 \mathrm{~km}$ (Fig. 1). The sequence data were used to determine the extent and nature of the genetic variation in $P$. xylostella populations in China.

\section{MATERIAL AND METHODS}

\section{Insects}

Each ten diamondback moths were collected from six Chinese localities (Fig. 1 and Table 1). Two Korean localities were included to determine the haplotype divergence between Chinese and Korean populations. Samples were frozen at $-20^{\circ} \mathrm{C}$ until used for molecular analysis.

\section{Amplification of mitochondrial $\mathrm{COI}$ gene}

Total DNA was extracted using the Wizard ${ }^{\mathrm{TM}}$ Genomic DNA Purification Kit (Promega, Madison, WI, USA). For the amplification of a 681-bp portion of $\mathrm{mt} C O I$ gene, a pair of primers was designed by aligning published complete lepidopteran genome sequences (Yukuhiro et al., 2002): 5'-AAATTTACAA TTTATCGCTTAAATCTCAGCC-3' for forward and 5'CCTCTTTCTTGTGATAATAATATGGAAATTATACC-3' for reverse direction. This $C O I$ region is regularly used as a global bioidentification system for animals (Hebert et al., 2003). PCR amplification was performed on a Biometra thermal cycler

\footnotetext{
* Corresponding author; e-mail: brjin@dau.ac.kr
} 


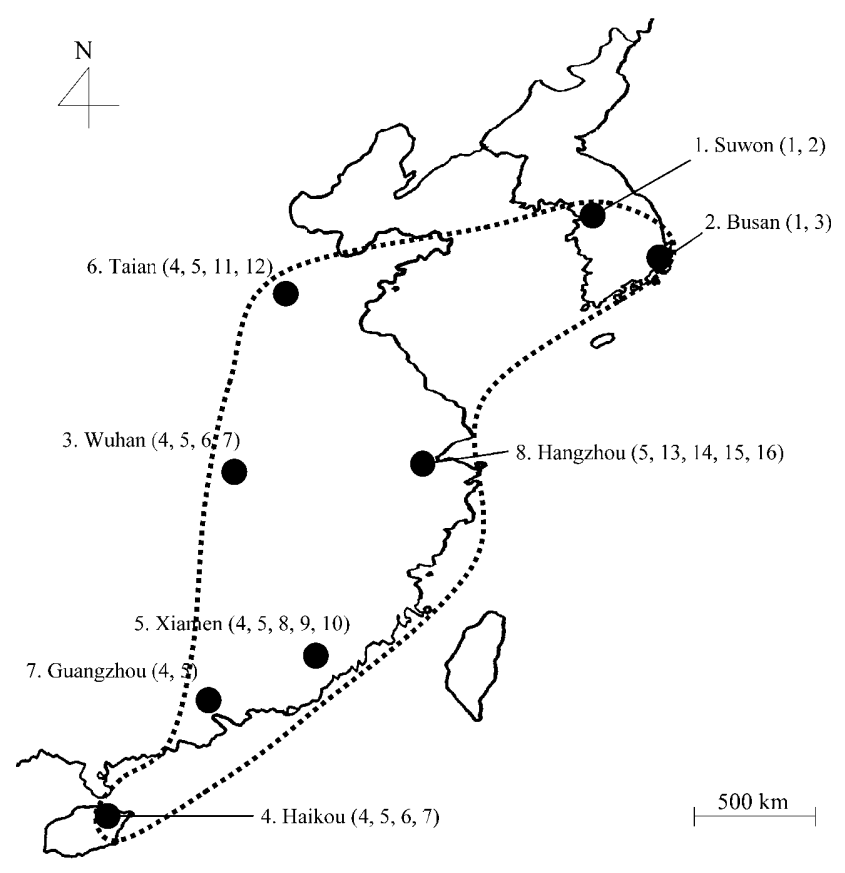

Fig. 1. A map of the locations where Plutella xylostella was sampled in China and Korea. General locality names are as follows: 1 - Suwon city, Kyunggi Province, Korea; 2 - Busan city, Korea; 3 - Wuhan, Hubei province, China; 4 - Haikou, Hainan province, China; 5 - Xiament, Fujian province, China; 6 Taian, Shandong province, China; 7 - Guangzhou, Guangdong province, China; and 8 - Hangzhou, Zhejiang province, China. Numbers in parenthesis are the haplotype designations omitting the preceding letters PX.

(model T-gradient Thermoblock, Biometra, Goettingen, Germany): initial denaturation for $5 \mathrm{~min}$ at $95^{\circ} \mathrm{C}$, followed by 35 cycles of $1 \mathrm{~min}$ at $94^{\circ} \mathrm{C}, 45 \mathrm{~s}$ annealing at $53^{\circ} \mathrm{C}$, and $1 \mathrm{~min}$ at $72^{\circ} \mathrm{C}$ and a subsequent $7 \mathrm{~min}$ final extension at $72^{\circ} \mathrm{C}$. To confirm the successful DNA amplification by PCR, electrophoresis was carried out using $0.5 \times$ TAE buffer on $1 \%$ agarose gel. The PCR product was then purified using a PCR purification Kit (Qiagen, Hilden, Germany). Both strands of the PCR amplicons were cycle-sequenced using the ABI PRISM ${ }^{\circledR}$ BigDye $^{\circledR}$ Terminator v1.1 Cycle Sequencing Kit and then subjected to electrophoresis in both directions on an ABI PRISM ${ }^{\mathrm{TM}} 310$ Genetic Analyzer (Perkin-Elmer Applied Biosystems, Foster City, CA, USA). Sequence alignment was performed using IBI MacVector (ver. 6.0, Oxford Molecular Ltd., Oxford, UK). When homologous sequences from two individuals differed by $\geq$ one nucleotide base, the sequences were considered as different haplotypes. Haplotype designations were applied to new sequences as they were discovered (PX1 PX2, PX3 and so on). GenBank accession numbers of each individual are listed in Table 1 .

\section{Phylogenetic analysis}

Phylogenetic analyses were performed using the maximumparsimony (MP) (Fitch, 1971) and maximum likelihood (ML) methods (Felsenstein, 1981) using PAUP* (Phylogenetic Analysis Using Parsimony and Other Method*) ver. 4.0b10 (Swofford, 2002). MP and ML analyses were performed by heuristic search by selecting tree-bisection-reconnection (TBR) option for branch swapping, stepwise addition option for starting tree, number of trees held at each step during stepwise addition for one, and initial "MaxTrees" setting for 100. For the

\begin{tabular}{|c|c|c|}
\hline & & $\begin{array}{l}2233344445556666 \\
5918924781784666 \\
5765907197902036\end{array}$ \\
\hline PX1 & --- & ACCTCCAGAAGCTAAG \\
\hline PX2 & --- & $\ldots \mathrm{T} \ldots \ldots \ldots \ldots$ \\
\hline PX3 & --- & .TT .......... \\
\hline PX4 & --- & $. \mathrm{TT} \ldots \mathrm{AG} \ldots . .$. \\
\hline PX5 & --- & .TT......... \\
\hline PX6 & --- & .TT.T........ \\
\hline PX7 & --- & . TC.T.G..... \\
\hline PX8 & --- & . T. . . . . . . \\
\hline PX9 & --- & .TT...AG.... . \\
\hline PX10 & --- & .TT ......... . \\
\hline PX11 & --- & .TT....G.A.... \\
\hline PX12 & --- & GTT $\ldots \ldots \ldots \ldots$ \\
\hline PX13 & --- & .TT.T........ \\
\hline PX14 & --- &. $\mathrm{TT} \ldots$. G.GG..... \\
\hline PX15 & --- & $. \mathrm{TT} \ldots \mathrm{AG} \ldots . \mathrm{G}$ \\
\hline PX16 & --- & $. \mathrm{TT} \ldots . \mathrm{G} \ldots . . \mathrm{A}$ \\
\hline
\end{tabular}

Fig. 2. Positions of 16 sites among 16 haplotypes obtained by sequencing 681-bp of COI gene of 80 Plutella xylostella. Only positions that differ from haplotype PX1 are indicated, and full sequences of the region were registered at the GenBank with the accession numbers as listed in Table 1.

ML analysis the HKY85 model, which allows for unusual base frequencies (Hasegawa et al., 1985) was used for the distance measure, as it is the most appropriate for the data. Branches were collapsed if maximum branch length is zero in MP analysis and if maximum branch length is less than or equal to one in the ML analysis. Trees were evaluated using the bootstrap test (Felsenstein, 1985) limited to 1,000 iterations for the MP and 100 iterations for the ML tree because of the time required for computation. To root the tree, the homologous region of the apple ermine moth, Yponomeuta malinellus Zeller (Sperling et al., 1995), which also belongs to the superfamily Yponomeutoidea, was utilized. This species was used as an outgroup, because it is taxonomically most similar to $P$. xylostella among the available homologus regions in the GenBank $(\sim 13 \%$ of sequence divergence from $P$. xyllostella). With intraspecific mtDNA sequence data it often happens that parsimony analysis provides limited resolution because of polytomies, possibly caused by back mutations and parallel mutations. One solution, employed here is to prepare one-step median networks, which provide insight into probable relationships among closely related lineages (Bandelt et al., 1995).

\section{Genetic distance and migration estimate}

Genetic distance and per-generation female migration rate between pairs of Chinese populations were estimated from mtDNA sequences and subroutines in the Arlequin ver. 2.0 (Schneider et al., 2000). Population pairwise genetic distance $\left(F_{\mathrm{ST}}\right)$ and a permutation test of the significant differentiation of the pairs of localities (1,000 bootstraps) were obtained following the approach described in Excoffier et al. (1992), and the distances between DNA sequences were calculated by Kimura's 2-parameters method (Kimura, 1980). Pairwise $F_{\mathrm{ST}}$ values were used to estimate per-generation female migration rate, $\mathrm{Nm}$ (the product of the effective population size $N_{e}$ and migration rate, $m$ ), based upon the equilibrium relationship: $F_{\mathrm{ST}}=1 /(2 \mathrm{Nm}+1)$. 
TABLE 1. Trapping localities, collection details and COI haplotypes of Plutella xylostella (L.) in China and Korea.

\begin{tabular}{|c|c|c|c|c|}
\hline Locality & Animal number & Date of collection & COI haplotype & Genbank Number \\
\hline \multirow[t]{10}{*}{ 1. Suwon City (Korea) } & SW1 & June 2004 & PX1 & DQ076332 \\
\hline & SW2 & , & PX2 & DQ076333 \\
\hline & SW3 & $"$ & PX1 & DQ076334 \\
\hline & SW4 & $"$ & PX1 & DQ076335 \\
\hline & SW5 & $"$ & PX1 & DQ076336 \\
\hline & SW6 & $"$ & PX1 & DQ076337 \\
\hline & SW7 & $"$ & PX2 & DQ076338 \\
\hline & SW8 & $"$ & $\mathrm{PX} 2$ & DQ076339 \\
\hline & SW9 & $”$ & PX2 & DQ076340 \\
\hline & SW10 & $"$ & PX1 & DQ076341 \\
\hline \multirow[t]{10}{*}{ 2. Busan City (Korea) } & BS1 & $"$ & PX3 & DQ076342 \\
\hline & BS2 & $"$ & PX3 & DQ076343 \\
\hline & BS3 & $"$ & PX3 & DQ076344 \\
\hline & BS4 & $"$ & PX1 & DQ076345 \\
\hline & BS5 & $"$ & PX1 & DQ076346 \\
\hline & BS6 & $"$ & PX1 & DQ076347 \\
\hline & BS7 & $"$ & PX1 & DQ076348 \\
\hline & BS8 & $"$ & PX1 & DQ076349 \\
\hline & BS9 & $"$ & PX1 & DQ076350 \\
\hline & BS10 & $”$ & PX1 & DQ076351 \\
\hline \multirow[t]{10}{*}{ 3.Wuhan, Hubei province (China) } & WH1 & Sept. 2004 & PX4 & DQ076352 \\
\hline & WH2 & , & PX4 & DQ076353 \\
\hline & WH3 & $"$ & PX4 & DQ076354 \\
\hline & WH4 & $"$ & PX4 & DQ076355 \\
\hline & WH5 & $"$ & PX4 & DQ076356 \\
\hline & WH6 & $"$ & PX4 & DQ076357 \\
\hline & WH7 & $"$ & PX5 & DQ076358 \\
\hline & WH8 & $"$ & PX7 & DQ076359 \\
\hline & WH9 & $"$ & PX6 & DQ076360 \\
\hline & WH10 & $"$ & PX4 & DQ076361 \\
\hline \multirow[t]{10}{*}{ 4. Haikou, Hainan province (China) } & HN1 & Feb. 2004 & PX4 & DQ076362 \\
\hline & HN2 & , & PX7 & DQ076363 \\
\hline & HN3 & $"$ & PX6 & DQ076364 \\
\hline & HN4 & $"$ & PX4 & DQ076365 \\
\hline & HN5 & $"$ & PX7 & DQ076366 \\
\hline & HN6 & $"$ & PX7 & DQ076367 \\
\hline & HN7 & $"$ & PX7 & DQ076368 \\
\hline & HN8 & $"$ & PX5 & DQ076369 \\
\hline & HN9 & $"$ & PX7 & DQ076370 \\
\hline & HN10 & $"$ & PX5 & DQ076371 \\
\hline \multirow{10}{*}{ 5. Xiamen, Fujian province (China) } & XM1 & April 2004 & PX5 & DQ076372 \\
\hline & $\mathrm{XM} 2$ & , & PX4 & DQ076373 \\
\hline & XM3 & $"$ & PX8 & DQ076374 \\
\hline & XM4 & $"$ & PX4 & DQ076375 \\
\hline & XM5 & $"$ & PX4 & DQ076376 \\
\hline & XM6 & $"$ & PX4 & DQ076377 \\
\hline & XM7 & $"$ & PX5 & DQ076378 \\
\hline & XM8 & $"$ & PX4 & DQ076379 \\
\hline & XM9 & $"$ & PX9 & DQ076380 \\
\hline & XM10 & $"$ & PX10 & DQ076381 \\
\hline \multirow[t]{10}{*}{ 6. Taian, Shandong province (China) } & SD1 & Nov. 2004 & PX4 & DQ076382 \\
\hline & SD2 & , & PX4 & DQ076383 \\
\hline & SD3 & $"$ & PX4 & DQ076384 \\
\hline & SD4 & $"$ & PX11 & DQ076385 \\
\hline & SD5 & $"$ & PX5 & DQ076386 \\
\hline & SD6 & $"$ & PX11 & DQ076387 \\
\hline & SD7 & $"$ & PX11 & DQ076388 \\
\hline & SD8 & $"$ & PX12 & DQ076389 \\
\hline & SD9 & $"$ & $\mathrm{PX} 12$ & DQ076390 \\
\hline & SD10 & $"$ & $\mathrm{PX} 4$ & DQ076391 \\
\hline 7. Guangzhou, Guangdong province (China) & GZ1 & Nov. 2004 & PX4 & DQ076392 \\
\hline & GZ2 & , & PX5 & DQ076393 \\
\hline & GZ3 & $"$ & PX4 & DQ076394 \\
\hline & GZ4 & $"$ & PX5 & DQ076395 \\
\hline & GZ5 & $"$ & PX5 & DQ076396 \\
\hline & GZ6 & ” & PX4 & DQ076397 \\
\hline & GZ7 & $"$ & PX5 & DQ076398 \\
\hline & GZ8 & $"$ & PX4 & DQ076399 \\
\hline & GZ9 & $"$ & PX5 & DQ076400 \\
\hline & GZ10 & $"$ & PX4 & DQ076401 \\
\hline 8. Hangzhou, Zhejiang province (China) & $\mathrm{HZ1}$ & Nov. 2004 & PX13 & DQ076402 \\
\hline & $\mathrm{HZ} 2$ & " & PX14 & DQ076403 \\
\hline & $\mathrm{HZ} 3$ & $"$ & PX13 & DQ076404 \\
\hline & $\mathrm{HZ} 4$ & $"$ & PX5 & DQ076405 \\
\hline & $\mathrm{HZ} 5$ & $"$ & PX13 & DQ076406 \\
\hline & HZ6 & $"$ & PX13 & DQ076407 \\
\hline & $\mathrm{HZ7}$ & $"$ & PX15 & DQ076408 \\
\hline & HZ8 & $"$ & PX16 & DQ076409 \\
\hline & HZ9 & $"$ & PX13 & DQ076410 \\
\hline & HZ10 & $"$ & PX15 & DQ076411 \\
\hline
\end{tabular}


TABLE 2. Uncorrected pairwise comparison of nucleotide sequence of the mitochondrial COI gene of Plutella xylostella (L.)

\begin{tabular}{lllllllllllllllllllll}
\hline & & 1 & 2 & 3 & 4 & 5 & 6 & 7 & 8 & 9 & 10 & 11 & 12 & 13 & 14 & 15 & 16 & 17 \\
\hline 1 & PX1 & - & 0.001 & 0.003 & 0.006 & 0.004 & 0.006 & 0.006 & 0.006 & 0.007 & 0.006 & 0.006 & 0.004 & 0.004 & 0.007 & 0.007 & 0.006 & 0.129 \\
2 & PX2 & 1 & - & 0.001 & 0.004 & 0.003 & 0.004 & 0.004 & 0.004 & 0.006 & 0.004 & 0.004 & 0.003 & 0.003 & 0.006 & 0.006 & 0.004 & 0.128 \\
3 & PX3 & 2 & 1 & - & 0.003 & 0.001 & 0.003 & 0.006 & 0.006 & 0.004 & 0.003 & 0.003 & 0.001 & 0.001 & 0.004 & 0.004 & 0.003 & 0.126 \\
4 & PX4 & 4 & 3 & 2 & - & 0.001 & 0.006 & 0.006 & 0.006 & 0.001 & 0.003 & 0.003 & 0.004 & 0.004 & 0.004 & 0.001 & 0.003 & 0.126 \\
5 & PX5 & 3 & 2 & 1 & 1 & - & 0.004 & 0.004 & 0.004 & 0.003 & 0.001 & 0.001 & 0.003 & 0.003 & 0.003 & 0.003 & 0.001 & 0.128 \\
6 & PX6 & 4 & 3 & 2 & 4 & 3 & - & 0.009 & 0.009 & 0.007 & 0.006 & 0.006 & 0.004 & 0.001 & 0.007 & 0.007 & 0.006 & 0.126 \\
7 & PX7 & 4 & 3 & 4 & 4 & 3 & 6 & - & 0.003 & 0.007 & 0.006 & 0.006 & 0.007 & 0.007 & 0.007 & 0.007 & 0.006 & 0.128 \\
8 & PX8 & 4 & 3 & 4 & 4 & 3 & 6 & 2 & - & 0.007 & 0.006 & 0.006 & 0.007 & 0.007 & 0.007 & 0.007 & 0.006 & 0.131 \\
9 & PX9 & 5 & 4 & 3 & 1 & 2 & 5 & 5 & 5 & - & 0.001 & 0.004 & 0.006 & 0.006 & 0.006 & 0.003 & 0.004 & 0.126 \\
10 & PX10 & 4 & 3 & 2 & 2 & 1 & 4 & 4 & 4 & 1 & - & 0.003 & 0.004 & 0.004 & 0.004 & 0.004 & 0.003 & 0.128 \\
11 & PX11 & 4 & 3 & 2 & 2 & 1 & 4 & 4 & 4 & 3 & 2 & - & 0.004 & 0.004 & 0.004 & 0.004 & 0.003 & 0.126 \\
12 & PX12 & 3 & 2 & 1 & 3 & 2 & 3 & 5 & 5 & 4 & 3 & 3 & - & 0.003 & 0.006 & 0.006 & 0.004 & 0.128 \\
13 & PX13 & 3 & 2 & 1 & 3 & 2 & 1 & 5 & 5 & 4 & 3 & 3 & 2 & - & 0.006 & 0.006 & 0.004 & 0.128 \\
14 & PX14 & 5 & 4 & 3 & 3 & 2 & 5 & 5 & 5 & 4 & 3 & 3 & 4 & 4 & - & 0.006 & 0.004 & 0.129 \\
15 & PX15 & 5 & 4 & 3 & 1 & 2 & 5 & 5 & 5 & 2 & 3 & 3 & 4 & 4 & 4 & - & 0.004 & 0.128 \\
16 & PX16 & 4 & 3 & 2 & 2 & 1 & 4 & 4 & 4 & 3 & 2 & 2 & 3 & 3 & 3 \\
17 & Y. malinellus & 88 & 87 & 86 & 86 & 87 & 86 & 87 & 89 & 86 & 87 & 86 & 87 & 87 & 88 & 87 & 88 & -
\end{tabular}

Numbers above the diagonal are mean distance values; numbers below the diagonal are absolute distance values.

GenBank accession number of Y. malinellus is U09206 (Sperling et al., 1995).

\section{RESULTS}

\section{COI gene sequence analysis}

Sequence analysis of the $80 \mathrm{P}$. xylostella individuals collected at six Chinese and two Korean localities yielded a total of 16 haplotypes (PX1-PX16; Table 1). No length variation among haplotypes was detected. These haplotypes revealed 16 polymorphic sites, seven of which were $\mathrm{T} / \mathrm{C}$ transitions, eight $\mathrm{G} / \mathrm{A}$ transitions and one on $\mathrm{A} / \mathrm{C}$ transversion (Fig. 2). Nucleotide composition of 16 haplotypes ranged from $15.27-15.71 \%$ in $\mathrm{G}, 30.09-31.42 \%$ in $\mathrm{A}, 37.89-38.47 \%$ in $\mathrm{T}$ and $14.98-15.42 \%$ in $\mathrm{C}$. Thus,

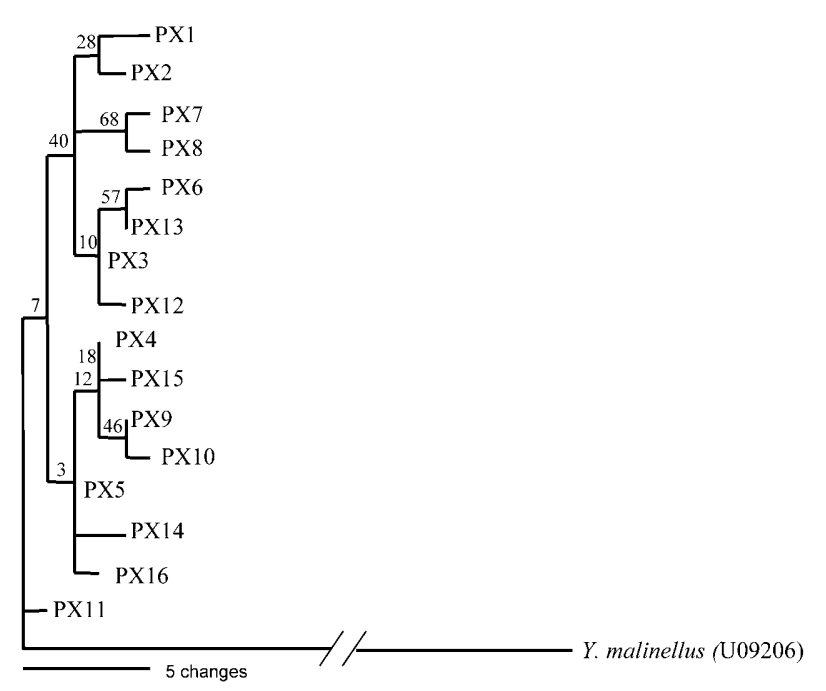

Fig. 3. Phylogenetic analysis of mitochondrial COI gene sequences of Plutella xylostella. The tree was obtained by the MP method incorporated in PAUP* (Phylogenetic Analysis Using Parsimony and Other Method*) ver 4.0b10 (Swofford, 2002). The numbers on/below the branches represent bootstrap values for 1,000 replications. Tree length is 104 steps, Consistency Index is 0.942 , Retention Index is 0.667 and Homoplasy Index is 0.058. Yponomeuta malinellus (Sperling et al., 1995), which also belongs to the superfamily Yponomeutoidea together with $P$. xylostella, was utilized as an outgroup. the $\mathrm{A}+\mathrm{T}$ nucleotide bias in the animal $\mathrm{mt}$ genome (Boore, 1999.) was detected also in the P. xylostella COI gene sequence. Thirteen of the 16 polymorphic sites were third codon positions and the remaining three first positions (nucleotide positions 316,385 , and 580), but there were no amino acid substitutions.

\section{Haplotype divergence}

Uncorrected pairwise distance comparisons among $P$. xylostella haplotypes ranged from $0.1 \%$ (one nucleotide) to $0.9 \%$ (six nucleotides). The largest sequence divergence was found when haplotype PX6 was compared with PX7 and PX8 (Table 2).

None of the haplotypes found in the Korean moths were found in the Chinese moths and vice versa. Eleven of the 16 haplotypes were found only at a single locality and only three haplotypes (PX1, PX6, and PX7) were found at two localities, indicating that most haplotypes are locally restricted (Table 1). However, haplotypes PX4 and PX5 are noteworthy in that these occur at almost all the Chinese localities surveyed (PX4 at five and PX5 at six localities). Collectively, the distribution can be characterized as the co-existence of mainly locally restricted and a few extensively distributed haplotypes.

Uncorrected pairwise distances of the three haplotypes found at the Korean localities (PX1, PX2, and PX3) to the Chinese samples ranged from $0.1 \%$ to $0.7 \%$, whereas the estimates among Chinese samples ranged from $0.1 \%$ to $0.9 \%$ (Table 2). Thus, the within-divergence estimate for the Chinese samples is similar to the between-divergence estimate of the Korean and Chinese samples. This seems to indicate that the Chinese samples do not differ from the Korean samples. Moreover, haplotypes PX5, PX12 and PX13 obtained from China showed a minimal distance to PX3, which was found exclusively in the Korean samples, indicating that the haplotypes found in each territory are similar (Table 2 ). 


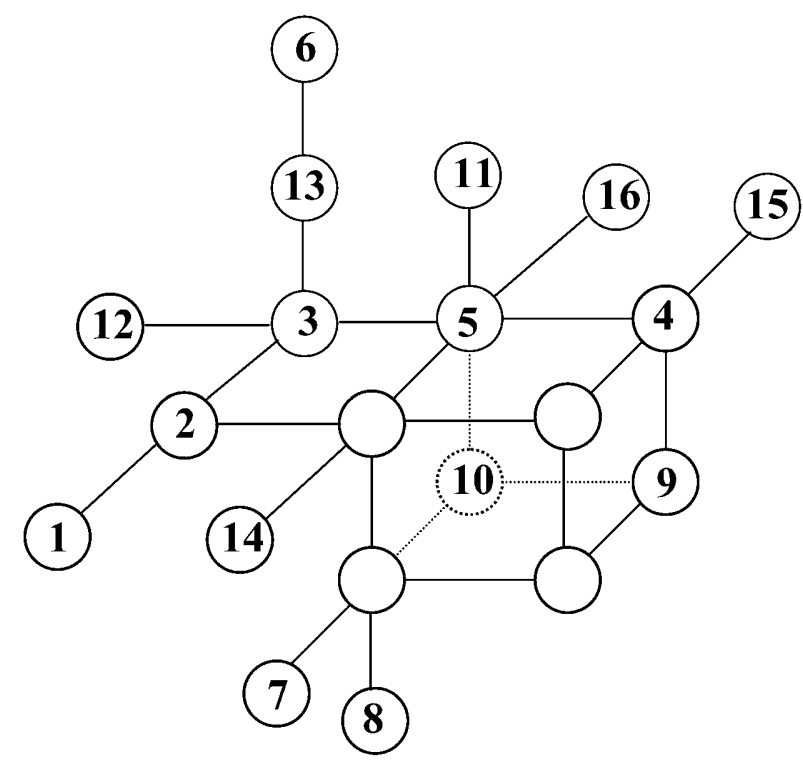

Fig. 4. Parsimonious one-step median network illustrating the relationships of the Plutella xylostella revealed by sequencing a $681 \mathrm{bp}$ fragment of COI. Each bar indicates one nucleotide difference from the neighbouring haplotype and empty circles indicate the haplotypes that were not found in this study. Numbers in each circle denote haplotype name, omitting the preceding letters, PX.

\section{Phylogenetic and network analyses}

Phylogenetic relationships among haplotypes are depicted in Fig. 3. Because analyses run with transition: transversion weightings of $1: 0,1: 1,1: 5,1: 10$, and $1: 20$ did not affect the topology of the tree, the result obtained by unordered analysis only is presented (Fig. 3). Most haplotypes were weakly associated (less than $50 \%$ bootstrap support) or unresolved due possibly to small nucleotide difference among them (Table 2). Haplotype groups, PX7/PX8 (68\%) and PX6/PX13 (57\%), obtained marginal support as inclusive groups (Fig. 3). To further illustrate the genetic relationships among $P$. xylostella haplotypes, an unrooted one-step median network, which visualizes a possible evolutionary pathway among closely related haplotypes, was obtained (Fig. 4). Although more resolution among closely related haplotypes was expected, the analysis provided limited information. For example, the network suggested that no haplotype or hap- lotype group had diverged, and, in fact, all haplotypes were highly interconnected with each other. The MLbased phylogenetic analysis gave on almost identical topology to the MP method (data not shown).

\section{Gene flow}

Genetic distance $\left(F_{\mathrm{ST}}\right)$ and per-generation female migration rate $(\mathrm{Nm})$ between pairs of Chinese populations are shown in Table 3. Pairwise genetic distance $\left(F_{\mathrm{ST}}\right)$ among 15 pairs of Chinese populations ranged from -0.038 to 0.309 . Among them, eight showed statistically no significant genetic differentiation $(p>0.05)$, suggesting that several pairs of populations form one genetic group (Table 3). Per-generation female migration rate $(\mathrm{Nm})$ among 15 pairs of Chinese populations ranged from 1.117 to infinite. Thus, more than one female diamondback moth per generation were estimated to migrate between all pairs of populations, indicating that there is a substantial gene flow between most Chinese populations.

\section{DISCUSSION}

The maximum mtDNA sequence divergence in $P$. xylostella was $0.9 \%$. In other insects, the maximum sequence divergence is $0.2 \%$ for the domestic silkworm (Kim et al., 2000b), $0.2 \%$ and $1.2 \%$ for two species of mushroom fly (Bae et al., 2001), $\sim 0.23 \%$ and $0.12 \%$ for two species of the rice planthoppers (Mun et al., 1999), $0.4 \%$ for spruce budworm species (Sperling \& Hickey, 1994), $0.5 \%$ for Heliconius butterflies (Brower, 1994) and $4.0 \%$ for the firefly, Luciola lateralis Motschulsky (Kim et al., 2001). Excluding L. lateralis, which seems to include more than one species (Kim et al., 2001), it was approximately $\leq 1.2 \%$ for the insect $\mathrm{mt} C O I$ gene. Thus, the magnitude of sequence divergence in P. xylostella is comparable with that revealed in similar studies.

Phylogenetic analyses of $P$. xylostella suggested that no notable polymorphic haplotype or haplotype group was present in the Chinese populations on the two Korean populations. A similar result was reported by Kim et al. (2003), wherein most nodes were very weakly supported or unresolved, indicating close phylogenetic relationships among $P$. xylostella haplotypes. Further, the populationbased analysis also indicated that many $P$. xylostella populations are genetically similar to each other, with a high gene flow rate (Table 3). In particular, haplotypes

TABLE 3. Genetic distance and per-generation female migration rate between pairs of Chinese localities based on mitochondrial COI sequence of Plutella xylostella (L.)

\begin{tabular}{lcccccc}
\hline & 1 & 2 & 3 & 4 & 5 & 6 \\
\hline 1. Wuhan & - & 0.19382 & -0.03801 & 0.06173 & -0.01010 & $0.18871^{*}$ \\
2. Haikou & 2.07974 & - & $0.22723^{*}$ & $0.25287^{*}$ & $0.30918^{*}$ & $0.26251^{* * *}$ \\
3. Xiamen & inf & 1.70037 & - & 0.06977 & -0.02222 & $0.23611^{*}$ \\
4. Taian & 7.60000 & 1.47727 & 6.66667 & - & 0.05556 & 0.15301 \\
5. Guangzou & inf & 1.11719 & inf & 8.50000 & - & $0.25556^{*}$ \\
6. Hangzhou & 2.14953 & 1.40470 & 1.61765 & 2.76786 & 1.45652 & - \\
\hline
\end{tabular}

Note: Distance was calculated by Kimura's 2-parameter method (Kimura, 1980). Values above diagonal are the estimate of genetic distance $\left(F_{\mathrm{ST}}\right)$; values below diagonal are the estimate of per-generation female migration rate $(\mathrm{Nm}) .{ }^{*} p<0.05 \%$; ${ }^{* *} p<0.01 \%$; and $* * * p<0.001 \%$. Inf means infinite. 
PX4 and PX5 were found at almost all Chinese localities surveyed (Table 1). Considering the geographic distances (Fig. 1) the occurrence of identical haplotypes over such a wide area is noteworthy. Previously, Kim et al. (2000a) also reported similar result, as one Hawaiian P. xylostella showed only one nucleotide difference from one of the Korean haplotypes. Occurrence of identical haplotypes over a wide area is also reported for other insect pests, such as the white pine weevil, Pissodes strobi (Peck) (Langor \& Sperling, 1995) and mushroom fly, Coboldia fuscipes (Meigen) (Bae et al., 2001). Thus, it seems that this feature is characteristic of cosmopolitan insect pests. However, identical haplotypes were not found in the Korean and Chinese moths, although some haplotypes were commonly found in each country. This may be because our sample sizes were relatively small and no northern localities were sampled in China and Korea (Fig. 1). Thus, larger sample sizes from more localities should provide a better understanding of the relationships between Korean and Chinese moths.

Avise et al. (1987) proposed a distribution pattern of mtDNA clones that can be summarized into phylogenetic continuity, an absence of regional isolation of mtDNA clones, and extensive distribution of close clones. Such a distribution was suggested to occur in those species that were extensively connected within the range of these species or had experienced recent historical interconnections through gene flow (Avise et al., 1987). The preliminary condition for such a distribution is the absence of firm and longstanding zoogeographic barriers to movement, as well as possession of biological features conductive to dispersal (Avise et al., 1987).

Diamondback moths quickly become abundant as they are highly fecund, develop quickly and complete many generations per year (Talekar \& Shelton, 1993). Furthermore, a substantial proportion $(7.8 \%$ per day) emigrate (Caprio \& Tabashnik, 1992) and the distance they migrate can be several thousand kilometers (Lorimer, 1981). Recent radar data also support long-distance migration in P. xylostella (Chapman et al., 2002). Thus, the life-history and ecological characteristics of $P$. xylostella seem to be concordant with the result of the phylogenetic analysis and estimate of gene flow ratio obtained in this study. Nevertheless, for a more decisive conclusion more samples from a greatest diversity of habitats need to be analyzed.

ACKNOWLEDGEMENT. This paper was supported by the Dong-A University Research Fund.

\section{REFERENCES}

Avise J.C., Arnold J., Ball R.M., Bermingham E., Lamb T., Neigel J.E., Reeb C.A. \& SAunders N.C. 1987: Intraspecific phylogeography: the mitochondrial DNA bridge between population genetics and systematics. Annu. Rev. Ecol. Syst. 18: $489-522$.

BAe J.S., KIM I., Kim S.R., JiN B.R. \& SohN H.D. 2001: Mitochondrial DNA sequence variation of the mushroom pest flies, Lycoriella mali (Diptera: Sciaridae) and Coboldia fuscipes (Diptera: Scatopsidae), in Korea. Appl. Entomol. Zool. 36: $451-457$.
BaKer G.J. \& Kovaliski J. 1999 Detection of insecticide resistance in Plutella xylostella (L.) (Lepidoptera: Plutellidae) populations in South Australian crucifer crops. Aust. J. Entomol. 38: 132-134.

Bandelt H.-J., Forster P., Sykes B.C. \& Richards M.B. 1995: Mitochondrial portraits of human populations using median networks. Genetics 141: 743-753.

Boore J.L. 1999: Animal mitochondrial genomes. Nucl. Acids Res. 27: 1767-1780.

Brower A.V.Z. 1994: Phylogeny of Heliconius butterflies inferred from mitochondrial DNA sequences (Lepidoptera: Nymphalidae). Mol. Phylogenet. Evol. 3: 59-174.

Brown W.M., Prager E.M., Wang A. \& Wilson A.C. 1982: Mitochondrial DNA sequence of primates: tempo and mode of evolution. J. Mol. Evol. 18: 225-239.

Capinera J.L. 2001: Handbook of Vegetable Pests. Academic Press, San Diego, 729 pp.

CAPrio M.A. \& TABAShNIK B.E. 1992: Allozymes used to estimate gene flow among populations of diamondback moth (Lepidoptera: Plutellidae) in Hawaii. Environ. Entomol. 21: 808-815.

Chang W.X.Z., Tabashnik B.E., Artelt B., Malvar T., BallESTER V., Ferré J. \& Roderick G.K. 1997: Mitochondrial DNA sequence variation among geographic strains of diamondback moth (Lepidoptera: Plutellidae). Ann. Entomol. Soc. Am. 90: 590-595.

Chapman J.W., Reynolds D.R., Smith A.D., Riley J.R., Pedgley D.E. \& WoIwOD I.P. 2002: High-altitude migration of the diamondback moth Plutella xylostella to the U.K.: a study using radar, aerial netting, and ground trapping. Ecol. Entomol. 27: 641-650.

Excoffier L., Smouse P.E. \& Quattro J.M. 1992: Analysis of molecular variance inferred from metric distances among DNA haplotypes: application to human mitochondrial DNA restriction data. Genetics 131: 479-491.

FelsENSTEIN J. 1981: Evolutionary trees from DNA sequences: a maximum likelihood approach. J. Mol. Evol. 17: 368-376.

Felsenstein J. 1985: Confidence limits on phylogenics: an approach using the bootstrap. Evolution 29: 783-791.

Fitch W.M. 1971: Toward defining the course of evolution: minimal change for a specific tree topology. Syst. Zool. 20: 406-416.

HARRISON R.G. 1989: Animal mitochondrial DNA as a genetic marker in population and evolutionary biology. Trends Ecol. Evol. 4: 6-11.

Hasegawa M., Kishino H. \& Yano T. 1985: Dating of the human-ape splitting by a molecular clock of mitochondrial DNA. J. Mol. Evol. 22: 160-174.

Hebert P.D., Cywinska A., Ball S.L. \& de Waard J.R. 2003: Biological identification through DNA barcodes. Proc. $R$. Soc. Lond. (B) 270: 313-321.

Huang J. \& Wu W. 2003: Advance of studies on insecticide resistance to diamondback moth (Plutella xylostella L.). $J$. Guizhou Univ. 20: 97-104.

Kim I., Bae J.S., Choi K.H., Jin B.R., Lee K.R. \& Sohn H.D. 2000a: Haplotype diversity and gene flow of the diamondback moth, Plutella xylostella (Lepidoptera: Yponomeutidae), in Korea. Korean J. Appl. Entomol. 39: 43-52.

Kim I., Bae J.S., Sohn H.D., Kang P.D., Ryu K.S., Sohn B.H., JEONG W.B. \& JIN B.R. 2000b: Genetic homogeneity in the domestic silkworm, Bombyx mori, and phylogenetic relationship between B. mori and wild silkworm, B. mandarina, using mitochondrial COI gene sequences. Int. J. Indust. Entomol. 1: 9-17. 
Kim I., Bae J.S., Lee K.S., Kim E.S., Lee H.S., Ryu K.S., Yoon H.J., JiN B.R., Moon B.J. \& SoHN H.D. 2003: Mitochondrial COI gene sequence-based population genetic structure of the diamondback moth, Plutella xylostella, in Korea. Korean $J$. Genetics 25: 155-170.

Kim J.G., Kim I., Bae J.S., Jin B.R., Кim K.Y., Кim S.E., ChOI Y.C., Chol J.Y., Lee K.Y., Sohn H.D. \& Noh S.K. 2001: Genetic subdivision of the firefly, Luciola lateralis (Coleoptera: Lampyridae), in Korea detected by mitochondrial COI gene sequences. Korean J. Genetics 23: 203-219.

KIм Y., Kıм K. \& Kıм N. 1999: Genetic difference between two field populations of Plutella xylostella (Linné) based on four polymorphic allozymes. J. Asia-Pacific Entomol. 40: 227-233.

KimURA M. 1980: A simple method for estimating evolutionary rate of base substitution through comparative studies of nucleotide sequences. J. Mol. Evol. 16: 111-120.

LANGor D.W. \& Sperling F.A.H. 1995: Mitochondrial DNA variation and identification of bark weevils in the Pissodes strobe species group in western Canada (Coleoptera: Curculionidae). Can. J. Entomol. 127: 895-911.

LORIMER R.I. 1981: Lepidoptera immigrants to Orkney in 1890: Proc. T. Brit. Entomol. Nat. Hist. Soc. 14: 108-109.

Lu L.H., HE Y.R. \& PANG X.F. 2003: Effects of cruciferous vegetables on natural populations of the diamondback moths, Plutella xylostella L. (Lepidoptera: Plutellidae). Acta Ecol. Sin. 23: 2624-2630.

Mun J.H., Song Y.H., Heong K.L. \& Roderick G.K. 1999: Genetic variation among Asian populations of rice planthoppers, Nilaparvata legens and Sogatella furcifera (Hemiptera: Delphacidae): mitochondrial DNA sequences. Bull. Entomol. Res. 89: 245-253.
Schneider S., Roessli D. \& Excofier L. 2000: Arlequin: A software for population genetics data analysis. ver 2.0. Genetics and Biometry Lab, Dept. of Anthropology, Univ. Geneva.

Simon C., Frati F., Beckenbach A., Crespi B., Liu H. \& Flook P. 1994: Evolution, weighting, and phylogenetic utility of mitochondrial gene sequences and a composition of conserved polymerase chain reaction primers. Ann. Entomol. Soc. Am. 87: 651-701.

SperLing F.A.H. \& Hickey D.A. 1994: Mitochondrial DNA sequence variation in the spruce budworm species complex (Choristoneura: Lepidoptera). Mol. Biol. Evol. 11: 656-665.

Sperling F.A.H., LANDRY J. \& Hickey D.A. 1995: DNA-based identification of introduced ermine moth species in North America (Lepidoptera: Yponomeutidae). Ann. Entomol. Soc. Am. 88: 155-162.

SwOFFord D.L. 2002: PAUP*: Phylogenetic Analysis Using Parsimony (*and other methods). ver. 4.10. Sinauer Associates, Sunderland, MA.

Talekar N.S. \& Shelton A.M. 1993: Biology, ecology, and management of the diamondback moth. Annu. Rev. Entomol. 38: $275-301$.

Wilson A.C., Cann R.L., Carr S.M., George M., Gyllenstein U.B., Helm-Bychowski K.M., Highchi R.G., Palumbi S.R., Prager E.M., Sage R.D. \& Stoneking M. 1985: Mitochondrial DNA and two perspectives on evolutionary genetics. Biol. J. Linn. Soc. 26: 375-400.

Yukuhiro K., Sezutsu H., Itoh M., Shimizu K. \& Banno Y. 2002: Significant levels of sequence divergence and gene rearrangements have occurred between the mitochondrial genomes of the wild mulberry silkmoth, Bombyx mandarina, and its close relative, the domesticated silkmoth, Bombyx mori. Mol. Biol. Evol. 19: 1385-1389.

Received October 31, 2005; revised and accepted January 30, 2006 